\title{
Measuring Pupils' Attitudes Towards Socioscientific Issues
}

\section{Development and Validation of a Questionnaire}

\author{
Lida T. Klaver ${ }^{1}$ (D) - Juliette H. Walma van der Molen ${ }^{2}$
}

Accepted: 29 October 2020/Published online: 26Novem ber2020

(C) Springer Nature B.V. 2020

\begin{abstract}
This paper presents the results of a large-scale study to validate a questionnaire that measures pupils' attitudes towards socioscientific issues (the PASSI questionnaire). We define socioscientific issues (SSI) as those topics that are about complex societal and technological developments that may induce ethical dilemmas. In this study, the term attitudes describes a combination of attitude components that relate to pupils' engagement with SSI. Based on a literature review within social and educational psychology and sociology, on topics such as attitude development, scientific citizenship, social or civic engagement, and SSI teaching and learning, we developed a framework that describes several underlying components of pupils' attitudes towards SSI. These components were translated into nine scales that comprise the PASSI. Results of a validation study among 1370 pupils (age 8-15), using exploratory factor analyses on subsample 1 and subsequently confirmatory factor analyses on subsample 2, indicated an eight-factor structure that showed good convergent and discriminant validity. Furthermore, the PASSI instrument showed adequate measurement invariance for boys and girls, pupils in primary and secondary education, and for pupils at different secondary educational tracks. The results are discussed in terms of directions for future research to further investigate the validity of the PASSI questionnaire. To conclude, the PASSI questionnaire validly measures eight attitudes towards SSI and could serve as a tool that raises awareness of pupils' engagement with SSI. It can be used by researchers and teachers as a diagnostic instrument, to compare groups, and to study effects of SSI education.
\end{abstract}

\section{Introduction}

"It is time for action" (Hodson 2003, p. 645). More than 15 years ago, Hodson already argued that it was time for a science curriculum oriented towards socio-political action that meets the

Lida T. Klaver

1.t.klaver@saxion.nl

1 Saxion University of Applied Sciences, Deventer, The Netherlands

2 University of Twente, Enschede, The Netherlands 
needs, interests, and aspirations of young citizens. Scientific and technological innovations, as well as the commercialization, industrialization, and militarization of science, had raised new moral-ethical questions, and citizens were increasingly asked to engage in decisions that relate to such scientific and technological innovations. Therefore, according to Hodson, scientific illiteracy could impede the empowerment of citizens.

In our rapidly changing technological society, the urgency for this call for action is even more important. Development of a functional kind of scientific literacy is needed, focused on the use of scientific literacy to think about issues in everyday life (Hodson 2003; Zeidler and Nichols 2009) and the personal cognitive and moral development of students (Zeidler et al. 2005). In this sense, the primary goal of science education should be "supporting the development of students to be more informed and to be engaged citizens" (Sadler 2011, p. 3).

A science curriculum focused on citizenship should meet the needs, interests, and aspirations of all students (Osborne and Dillon 2008). It should not aim to supply the next generation of scientists, but it should aim to improve all students' ability to engage in societal issues that are related to scientific and technological developments. Although students cannot be expected to be able to fully understand such issues as an individual, Dewey argued that groups, under the right circumstances, can (Feinstein 2015). Science education that supports scientific citizenship should learn from science communication: it should see science news as embedded in contemporary social concerns and examine different people's perspectives (Feinstein 2015). Although several studies have shown that around $75 \%$ of teachers support the inclusion of such socioscientific issues (SSI) in the curriculum (Lee et al. 2006; Özden 2015; Parr 2014), it is argued that teachers generally use SSI to create interest when introducing a topic, but do not stress ethical issues or awareness of the interdependence between society and science (Ekborg et al. 2013).

The Science Technology and Society (STS) movement can be seen as the main educational response to the aforementioned changes in society (Hodson 2003). However, the STS movement and its successor, the Science Technology Society Environment (STSE) movement, were not without critique. Hodson (2003) and Zeidler et al. (2005) argued that a well-developed theoretical framework was lacking and little change in science curricula was brought about. Moreover, ethical issues and moral development were not considered (Zeidler et al. 2005). Since this critique on STS and Hodson's call for action, the SSI movement has taken steps forward (e.g., Levinson et al. 2017; Sadler et al. 2017; Zeidler 2016).

The SSI framework for science education is grounded in empirical research, aligned with a progressive paradigm of instruction, where knowledge is derived through evidence-informed reasoning (Zeidler 2014). Compared to STS, SSI researchers focus more on curricular change (Sadler et al. 2017) and political and value education (Sadler 2011). In addition, ethical dimensions of science and moral reasoning are considered (Zeidler and Sadler 2008). Where STS(E) mainly focuses on engaging students through social contexts for science content learning, the SSI framework emphasizes "the formation of virtue and character as longrange pedagogical goals" (Zeidler 2014, p. 699) and "empowering students to handle the science-based issues that shape their current world and those which will determine their future world" (Sadler 2004, p. 514).

\section{Engagement with Socioscientific Issues}

One of the citizenship goals of SSI teaching is to improve engagement with SSI. Engagement is "one of the most widely misused and overgeneralized constructs found in the educational, 
learning, instructional, and psychological sciences" (Azevedo 2015). It is often seen as being composed of interrelated aspects of behavior, emotion, and cognition (e.g., Fredricks et al. 2004). The concept of engagement is widely used: to describe student academic performance, classroom behaviors, approaches to interacting with instructional materials, motivational beliefs, affective states, self-regulation, and more (Azevedo 2015). Moreover, it can refer to individual engagement as well as collective engagement (Olitsky and Milne 2012; Sinatra et al. 2015). Despite (or maybe due to) the theoretical plurality and range of definitions of engagement (Azevedo 2015), it is "one of the hottest research topics in the field of educational psychology" and "could be described as the holy grail of learning" (Sinatra et al. 2015, p. 1). Engagement is also a widely used concept in the context of political and civic engagement (e.g., McIntosh and Youniss 2010; Schulz et al. 2010) and public engagement with science (e.g., Bandelli and Konijn 2015; Elam and Bertilsson 2003; Irwin 2001). In addition to theoretical difficulties with the concept of engagement, measuring engagement raises problems (Azevedo 2015; Sinatra et al. 2015). A wide range of methods is used to measure engagement, but these are not all suitable for measuring the diverse aspects of engagement (Azevedo 2015).

In this study, we aim to measure attitudes that are indicative of engagement with SSI. Our focus is on measuring attitudes, since attitude theory provides clear insight in the potential attitude components that are predictive for intention and behavior (Ajzen and Fishbein 1980, 2005). As such, attitudes are often used as indicators of behavioral and cognitive engagement. Moreover, operationalizations of attitudes show some overlap with operationalizations of emotional engagement. Both often include enjoyment, perceptions of value, or interest (e.g., Bandelli and Konijn 2015; Chang et al. 2018; Sinatra et al. 2015; Topçu 2010). Theoretically, emotional engagement shows similarities with attitudes too (Sinatra et al. 2015). This suggests that attitudes may precede behavioral or cognitive engagement, but they could also be viewed as a type of engagement, namely, emotional engagement. Similarly, Olitsky and Milne (2012) argued that emotional engagement may precede behavioral and cognitive engagement.

To measure the diverse cognitive and metacognitive as well as affective and motivational processes related to engagement, self-report questionnaires are considered one of the suitable methods (Azevedo 2015). However, almost half of the questionnaires used in science education research appear to miss some essential components of psychometric evidence ${ }^{1}$ (Blalock et al. 2008). Moreover, when focusing on engagement with SSI, and more specifically attitudes indicative of engagement with SSI, no suitable questionnaire is available. Questionnaires in the field of engagement with SSI often measure positions on specific SSI (e.g., beliefs and feelings on genetically modified food, Rundgren 2011) or focus on environmental attitudes (e.g., Wray-Lake et al. 2010). In addition, questionnaires on perceptions of SSIbased learning (e.g., Ottander and Ekborg 2012; Rahayu et al. 2018; Subiantoro 2017), conditions for social engagement (e.g., Van den Wijngaard et al. 2015), civic attitudes and engagement (Schulz et al. 2010), and attitudes towards socioscientific reasoning (Chang et al. 2018) are available. Although closely related to engagement with SSI, the object of engagement in these questionnaires is more or less different, and essential psychometric evidence is often lacking (e.g., Rahayu et al. 2018).

Only Topçu (2010) developed a questionnaire in which the object of engagement is SSI in general: the Attitudes towards Socioscientific Issues Scale (ATSIS). Exploratory and confirmatory factor analyses on ATSIS data of two separate samples $(n=160$ and $n=216)$ resulted

\footnotetext{
${ }^{1}$ In this review, 66 questionnaires measuring attitudes towards science, scientific attitudes, nature of science, and/ or scientific career interests were included.
} 
in a three-factor solution with 30 items, showing good model fit and reliability. The ATSIS also showed concurrent validity, distinguishing between major and non-major students. The three dimensions in the ATSIS are interest and usefulness of SSI, liking of SSI, and anxiety towards SSI. However, we find the ATSIS not suitable for four reasons. First, for the development of the ATSIS, mainly literature about attitudes towards science (e.g., Osborne et al. 2003) was considered rather than literature on engagement with SSI, citizenship, or attitude theory. Second, although usefulness and liking of SSI are theoretically distinguished by Topçu, in the final questionnaire, these two concepts form one construct. This raises questions about the content validity of the ATSIS. Third, anxiety towards SSI is defined as "students have concerns and worry about SSI," but this factor is measured by items that are not easily interpretable and that seem to be about cognitive beliefs rather than affective feelings (e.g., "I think that social values suffer from the implementation of SSI", Topçu 2010, p. 58). Fourth, the ATSIS was developed to measure undergraduate students' attitudes towards SSI, while we aim to measure these among young pupils.

\section{Goals of the Study}

The measurement of engagement with SSI in young pupils is important because SSI teaching and learning should already take place in primary education. Burek and Zeidler (2015) argued that SSI teaching and learning is already important in primary education, because it provides meaningful informal learning opportunities that foster pupils' interest and critical thinking skills. Years of research in media psychology and communication science suggest that many pupils at the end of primary school are already highly interested in following the news and to a certain extent worried about environmental and political issues (e.g., Littledyke 2004; Notley et al. 2017; Walma van der Molen et al. 2002). It is important to foster these interests and attitudes.

With the Dutch research project "Working Together towards Scientific Citizenship," we aimed to promote SSI teaching and learning through the co-creation and investigation of learning activities. To better understand pupils' engagement with SSI, its development, and effects of SSI teaching, a valid and reliable measurement instrument was needed. Moreover, the development of the learning activities could be guided by a valid operationalization of engagement with SSI (Steinmetz et al. 2016). Therefore, with the present study, we aim to develop a questionnaire that is theoretically well grounded with a clearly defined attitude object and provide essential components of psychometric evidence.

In the following, first, the engagement object is described: SSI. Second, a theoretical framework is given for attitudes towards SSI. Based on this theoretical foundation, we developed and validated the Pupils' Attitudes towards Socioscientific Issues (PASSI) questionnaire.

\section{Socioscientific Issues}

SSI refer to the controversial issues that emerge from combining science and society (Sadler 2004, 2009). These issues involve ill-structured problems that lack clear-cut solutions. SSI reflect the interplay between societal issues and technological or scientific developments. Many complex societal issues, such as urbanization or globalization, ask for technological solutions. At the same time, 
technological developments (e.g., food or medical technologies) and scientific findings (e.g., about nano-science) may lead to complex ethical debates. SSI may be controversial when the science and technology involved are still disputed, when future developments are not yet known, and economic, political, religious, and environmental concerns clash (Hodson 2006). The range of issues falling under this description of SSI is wide: from issues related to human health to biotechnology and from energy resources and consumption to freedom and control in science and technology (Hodson 2003, p. 655).

\section{Attitudes Towards SSI}

The concept of attitudes has a strong theoretical foundation (e.g., Ajzen 1991; Albarracin and Shavitt 2018; Steinmetz et al. 2016; Van Aalderen-Smeets et al. 2012). Moreover, there is general agreement on the non-restrictive abstract umbrella definition of attitudes, provided by Eagly and Chaiken (1993, p. 1), that an attitude is "a psychological tendency that is expressed by evaluating a particular entity with some degree of favour or disfavour" (Ajzen 2001; Van Aalderen-Smeets et al. 2012). The three key features of attitudes are tendency, evaluation, and attitude object (Eagly and Chaiken 1993, 2007). Tendency is established by "evaluative mental residue of past experience" and means that attitudes can be more short-term or long-term and more conscious or unconscious (Ajzen 2011; Eagly and Chaiken 2007, p. 584). Evaluation means that the attitude object can be perceived as favorable or unfavorable. The attitude object can be any aspect of the individual's world, for example, a person, an institution, event, or behavior (Ajzen and Fishbein 1980, 2005). For attitudes to be predictive of a certain behavior, the attitude object needs to be that particular behavior (Ajzen and Fishbein 1980, 2005). Since in the present study, we aimed to develop a questionnaire that is predictive of engagement with SSI, our attitude objects are those kind of behaviors that are indicative of engagement with SSI: discussing, investigating, and solving SSI and thinking, worrying, and learning about SSI (e.g., Sadler 2011).

Despite general agreement on this umbrella definition of attitudes, several theoretical views exist on its conceptualization (e.g., Bohner and Dickel 2011; Eagly and Chaiken 2007; Van Aalderen-Smeets et al. 2012). The framework for teachers' attitudes towards science formed the theoretical basis for our questionnaire development (Asma et al. 2011; Van AalderenSmeets et al. 2012). This framework revises the tripartite model of attitude, based on a literature review, focus group, and the theory of planned behavior (TPB).

The tripartite model describes how the construct of attitude can be divided into three components: cognition, affect, and behavior (Eagly and Chaiken 1993). In contrast, the TPB excludes behavior as a component of attitude (Ajzen 1985, 1991). Instead, the TPB postulates that the intention to perform a behavior is the immediate determinant of the attempted action. Intention and actual control determine the actual behavior, and intentions are determined by the following: (a) attitudes towards trying the behavior (e.g., beliefs about the outcomes associated with the behavior), (b) subjective norms with respect to the behavior (e.g., beliefs about whether others think one should try to perform the behavior), and (c) perceived control over the behavior (e.g., beliefs about the ease or difficulty of performing the behavior). In line with the tripartite model, attitudes towards the behavior, as described in the TPB, can be distinguished in affective (e.g., pleasant-unpleasant) and evaluative (e.g., harmful-beneficial) beliefs about the outcomes associated with the behavior (Ajzen 1991, 2011; Ajzen and Driver 1991). Following the framework for teachers' attitudes towards science and the TPB, perceived control should be distinguished into beliefs about dependency on context factors (i.e., perceived controllability) and beliefs or feelings about self-efficacy (Ajzen 2002; Asma et al. 2011). 
Note that the tripartite model and TPB are both general attitude theories that also apply to pupils' attitudes towards SSI. However, the literature review and focus group by Van Aalderen-Smeets et al. (2012) and Asma et al. (2011), which also formed the framework for teachers' attitudes towards science, are not applicable to pupils' attitudes towards SSI. Therefore, a translation to this target group and attitude object was made in the present study.

\section{Development of the PASSI Questionnaire}

To develop a questionnaire that meets psychometric requirements, in the present study, we followed the framework described by Trochim and Donnelly (2006) to investigate the construct validity of our questionnaire. ${ }^{2}$ According to this framework, construct validity includes both translation validity and criterion validity.

Translation validity requires content validity: the underlying constructs of the questionnaire should be theoretically sound. In addition, face validity is required: the operationalized measures of the instrument should be representative of their corresponding theoretical constructs. Moreover, for a reliable and valid result, respondents must be able to correctly interpret the questionnaire items.

\subsection{Content Validity}

To establish content validity, we reviewed literature within sociology and social and educational psychology about topics such as attitude development (e.g., Ajzen 1991; Topçu 2010; Van Aalderen-Smeets et al. 2012; Vogel and Wänke 2016), scientific citizenship (e.g., Bauer et al. 2012; Elam and Bertilsson 2003; Guérin 2018; Kolstø 2001), social or civic engagement (Azevedo 2015; Sinatra et al. 2015), and SSI teaching and learning (e.g., Romine et al. 2017; Sadler 2011; Zeidler and Nichols 2009). Subsequently, we developed a framework that describes pupils' attitudes towards SSI, consisting of nine attitudinal components that are described below (see Table 1).

\subsubsection{Relevance Institutions}

Solving SSI, which are controversial and complex issues, often requires action from governments and democratic institutions (e.g., amending laws). Therefore, engagement with SSI can also mean demanding action (e.g., Elam and Bertilsson 2003). Think for example of the "school strike for climate movement" where pupils demanded action from governments, public organizations, and companies. Trend data about adolescents' environmental attitudes, beliefs, and behaviors from 1976 to 2005 showed that youth considered the government's responsibility to solve environmental issues larger than their personal responsibility (WrayLake et al. 2010). Beliefs about the relevance of public organizations engaging with SSI are therefore important indicators of attitudes towards one's own engagement with SSI.

\subsubsection{Personal Relevance}

For pupils to get involved with SSI, it is necessary that they find their engagement in some way personally relevant (McIntosh and Youniss 2010; Wray-Lake et al. 2010). A study with 525

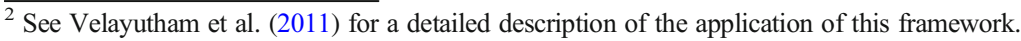


Table 1 The original nine scales of the PASSI questionnaire

\begin{tabular}{|c|c|c|}
\hline Scale & Description & Example item \\
\hline $\begin{array}{l}\text { Relevance Institutions } \\
\text { (RI) }\end{array}$ & $\begin{array}{l}\text { The degree to which pupils think it is } \\
\text { important that institutions act towards } \\
\text { solving SSI. }\end{array}$ & $\begin{array}{l}\text { I think it's very important that the } \\
\text { Government acts upon world issues. }\end{array}$ \\
\hline $\begin{array}{l}\text { Personal Relevance } \\
\quad(\mathrm{PR})\end{array}$ & $\begin{array}{l}\text { The degree to which pupils think it is } \\
\text { important that they, when they are } \\
\text { older, act towards solving SSI. }\end{array}$ & $\begin{array}{l}\text { To me, it's very important that I myself } \\
\text { will be able to help solve world issues } \\
\text { when I am older. }\end{array}$ \\
\hline Relevance School (RS) & $\begin{array}{l}\text { The degree to which pupils find it } \\
\text { important to learn about SSI at school. }\end{array}$ & $\begin{array}{l}\text { I think it's very necessary to learn about } \\
\text { world issues at school. }\end{array}$ \\
\hline $\begin{array}{l}\text { Relevance Science and } \\
\text { Technology (RST) }\end{array}$ & $\begin{array}{l}\text { The degree to which pupils believe } \\
\text { science and technology are relevant for } \\
\text { solving SSI. }\end{array}$ & $\begin{array}{l}\text { I think technology is very important to } \\
\text { solve world issues. }\end{array}$ \\
\hline Positive Feelings (PF) & $\begin{array}{l}\text { The degree to which pupils have positive } \\
\text { feelings when engaged in SSI. }\end{array}$ & $\begin{array}{l}\text { I really enjoy finding out more about } \\
\text { world issues. }\end{array}$ \\
\hline Concern $(\mathrm{CO})$ & $\begin{array}{l}\text { The degree to which pupils find SSI } \\
\text { worrisome. }\end{array}$ & These world issues really worry me. \\
\hline Self-Efficacy (SE) & $\begin{array}{l}\text { The degree to which pupils perceive } \\
\text { themselves able to engage in SSI. }\end{array}$ & $\begin{array}{l}\text { I am very good at investigating these } \\
\text { world issues. }\end{array}$ \\
\hline $\begin{array}{l}\text { Collective Efficacy } \\
\text { (CE) }\end{array}$ & $\begin{array}{l}\text { The degree to which pupils believe their } \\
\text { class is able to engage in SSI. }\end{array}$ & $\begin{array}{l}\text { I think my class is very good at } \\
\text { investigating these world issues. }\end{array}$ \\
\hline $\begin{array}{l}\text { Dependency on Others } \\
\text { (DO) }\end{array}$ & $\begin{array}{l}\text { The degree to which pupils feel dependent } \\
\text { on others for being engaged in SSI. }\end{array}$ & $\begin{array}{l}\text { I need the help of others to think about } \\
\text { solutions for world issues. }\end{array}$ \\
\hline
\end{tabular}

primary and secondary school pupils in England showed that a majority of pupils in primary school believed that they could bring about change through for example saving energy, recycling, or fundraising (Hicks and Holden 2007). Nevertheless, another study with focus groups in twelve Australian secondary schools suggested that pupils feel powerless to do something about SSI (Connell et al. 1999). Moreover, Barratt Hacking et al. (2007) argued that pupils often lack influence on the world around them. Therefore, we focus this dimension on pupils' beliefs about their personal relevance later on: do they think it is important that they play a role in solving SSI when they are grown up? This way, we measure pupils' beliefs about their personal relevance in solving SSI (which can be indicative of their current engagement with SSI), without interference of their feelings of powerlessness due to age.

\subsubsection{Relevance School}

Engaging with complex issues such as SSI requires knowledge and skills: the understanding and competence to comprehend and follow arguments about science and technology policy matters (Miller 2012). Therefore, engagement with learning about SSI in school activities also is a mode of pupils' engagement with SSI. Scientific content knowledge, knowledge about the nature of science, and higher-order thinking are outcomes often associated with SSI education (Sadler 2009). Pupils' attitudes towards learning about SSI can be measured by their beliefs about its importance.

\subsubsection{Relevance Science and Technology}

Science and technology are inherent in SSI. Knowledge about scientific and technological developments is necessary to understand these issues. People can believe that science and technology are important for solving SSI (Kim 2012), but people can also be concerned about 
science and technology as the source of SSI (Topçu et al. 2011). In this dimension, we focus on beliefs about the relevance of science and technology for solving SSI. Xiao and Sandoval (2017) studied the relations between attitudes towards science and evaluation of information about SSI (i.e., coal or nuclear power use) among 49 pupils (age 11-13). Pupils who believed science to be important for society were more likely to ask for extra scientific information before making a judgment. This study suggests that beliefs about the importance of science and technology are indicative of engagement with the scientific and technological aspects of SSI.

\subsubsection{Positive Feelings}

The TPB posits that the belief that a behavior will result in positive feelings is a determinant of one's attitudes and intentions towards that behavior, and one's feelings can determine which beliefs are salient (Ajzen 2011). These findings are corroborated by several studies. For example, PISA scores from 2006 showed that interest is closely related to enjoyment and they together affect the intention to further engage with science (Ainley and Ainley 2011). Another study with 153 upper secondary Norwegian students showed that their interest in SSI (i.e., climate change and nuclear power) was found to be positively related to their knowledge about the SSI (Stenseth et al. 2016). Moreover, the interactions between students' interest and knowledge were found to predict their personal stance on the issues. Note that the positive feelings scale in the PASSI questionnaire is focused on a combination of interest in SSI and enjoyment in engagement with SSI.

\subsubsection{Concern}

The negative feelings about SSI are feelings of concern. However, considering engagement, feelings of concern do not necessarily constitute a negative attitude. Several studies discuss the positive influence of feelings of concern on engagement (e.g., Bencze et al. 2012; Hicks and Holden 2007; Ryan and Spash 2012; Szagun and Pavlov 1995). For example, pupils feel concerned about environmental issues, war, unemployment, racism, and poverty (Hicks and Holden 2007; Littledyke 2004).

\subsubsection{Self-Efficacy}

Self-efficacy reflects the beliefs pupils have about their ability to engage with SSI (Bandura 2006). It is seen as one of the major factors determining civic engagement (Watts and Flanagan 2007; Wilkenfeld et al. 2010). Despite possible feelings of hopelessness about solving SSI (e.g., Connell et al. 1999), it could be that pupils belief themselves to be capable to engage with SSI (e.g., thinking about solutions for SSI or gathering information about SSI). Therefore, instead of solving SSI, the three perceived control dimensions (as well as the positive feelings dimension) refer to more realistic behaviors related to engagement with SSI.

\subsubsection{Collective Efficacy}

Self-efficacy is a well-known concept and often taken into consideration in attitude questionnaires (e.g., Rahayu et al. 2018; Van Aalderen-Smeets et al. 2012; Van den Wijngaard et al. 2015). However, political engagement requires collaboration with others to gain enough 
collective power to influence decision-making (McIntosh and Youniss 2010; Wilkenfeld et al. 2010), and important aspects of scientific citizenship are perspective taking and collective decision-making (Guérin 2018). Therefore, beliefs about the ability of the group to engage with SSI are important to consider. Bandura (2000, p. 75) defines collective efficacy as: "People's shared beliefs in their collective power to produce desired results." In the educational context of SSI teaching and learning, with collective efficacy, we refer to pupils' shared beliefs in the power of their class to engage with SSI.

\subsubsection{Dependency on Others}

While collective efficacy is a positive form of perceived control, the dimension dependency on others describes negative control beliefs related to engagement with SSI. This is the only dimension where a higher score is an indication of less engagement with SSI. Dependency on others refers to what Van Aalderen-Smeets et al. (2012) called "context dependency" and what Ajzen (2002) called "perceived controllability." It means that one believes to be dependent on others for engagement with SSI: to believe the help of others is needed. Characteristic for SSI is that they are often complex and that others are needed to find solutions. To take this into account, this scale also focuses on more realistic behaviors than solving SSI.

\subsection{Face Validity}

The nine components were translated into nine scales (see Table 1). Each subscale of the PASSI questionnaire originally consisted of five or six items representing the corresponding subcomponent of the framework. This original version of the PASSI consisted of 48 items to allow for the removal of possible problematic items later in the validation process. Each item in the PASSI questionnaire was formulated as a statement. Pupils' answers were assessed on a four-point Likert scale, with response scale options: (1) strongly disagree, (2) disagree, (3) agree, and (4) strongly agree.

\subsubsection{Likert Scale}

Although there are different methods to measure attitudes, such as semantic differential scales, direct interviews, or implicit testing, we chose a Likert scale because this method has several psychometric advantages. Likert-scale instruments are fit to include a large number of items organized in multiple subscales, they can be administered to a large number of respondents, the items can be answered quickly, and items can be combined to form composite scales that enable parametric testing (Boone and Boone 2012; Johns 2010; Krosnick 2018).

Likert-scale instruments are appropriate for our target group; other validation studies with young pupils that used Likert scales produced empirical data consistent with what was expected based on theory (e.g., Post and Walma van der Molen 2019). We used four-point Likert scales, rather than using an uneven number of response options, to ensure reliability: pupils may misinterpret the midpoint in an uneven scale as a neutral or do not know response or as a "dumping ground" for unsure or nonapplicable responses, which conceptually differs from a midpoint on a sliding scale (Kulas and Stachowski 2009; Kulas et al. 2008). 


\subsubsection{Pilot Tests}

After we formulated the items for each hypothesized subscale, we asked several experts in the fields of questionnaire design and attitude research to indicate whether the items were clearly formulated and representative of their corresponding scales. Subsequently, three teachers (primary and secondary) were asked to comment on whether they felt that the questionnaire was suitable for the target group and to propose improvements or additional items. A junior researcher did a walk-through of the questionnaire with eleven pupils of primary and secondary education, from different educational tracks, to verify if they understood the meaning of every item. Based on these pilots, some ambiguous or unclear items were adapted. In addition, to adjust the procedure to the needs of the target group, we decided that the questionnaire should be read aloud with pupils age eight till ten, because the youngest children showed some difficulty reading all the items.

We also observed that some pupils struggled with the Dutch term for "socioscientific issues." Therefore, we decided to pilot test several terms (i.e., world issues, complex issues, and developments in the world) with a brainstorm session with 21 pupils in primary education. Pupils' understanding of the term "world issues" best represented the meaning of SSI. The term world issues was therefore used in the questionnaire items and to explain SSI in the introduction of the questionnaire. This explanation included a description of what we mean by world issues, illustrated with two examples of SSI: (1) air pollution and cars and (2) drinking water shortages and textile. In this description, these world issues were also connected to pupils' own life. Local issues (e.g., clothing consumption) can often be translated to global issues (e.g., drinking water shortages) and the other way around (Hancock et al. 2019). To make sure the pupils understood the context of the questionnaire, a brainstorm about SSI and "world issues" was added to the start of the administration procedure. To be able to check pupils' interpretation of the term world issues, we added two open questions in the PASSI questionnaire: one about the world issues pupils think of and the other about professions needed to solve these issues. Overall, these pilot studies aided us in improving the face validity of the PASSI (see the "Results" section for pupils' answers on the two open questions).

\section{Investigation of Criterion Validity of the PASSI Questionnaire}

\subsection{Respondents}

The PASSI questionnaire was administered among a convenient but large-size sample of pupils $(N=1370)$ of ten public primary schools $(n=382)$ and seven public secondary schools $(n=988)$ in the East of the Netherlands. The sample consisted of twelve schools that participated in a 4-year research project entitled "Working together towards scientific citizenship," which we expanded with five more schools because a larger dataset was necessary to properly validate the questionnaire. During this expansion, we took into account that the sample would be properly mixed, regarding area (rural and urban), socioeconomic status, and education type. The sample included 660 boys and 710 girls. The respondents' ages ranged from 8 to 15 years $(M=11.98 ; \mathrm{SD}=1.35)$. 


\subsection{Procedure}

Questionnaires were administered in the period between September 2015 and January 2016. The questionnaires were administered after receiving passive informed consent from a responsible authority (parents or other caregivers). This procedure complies with the standards set by the ethical commission of our university.

A research assistant administered the questionnaire to all pupils in their own classroom during normal school hours. During the whole session, the research assistant was present to ensure that pupils filled in the whole questionnaire without interference of other pupils, to answer questions from pupils about the questionnaire, and to make sure that the administration procedure in every class was as much the same as possible. The questionnaire took about 25 min to complete. The research assistant started with a brainstorm about SSI and "world issues." The pupils named world issues and discussed what defines a world issue. Then, when possible, pupils received a digital version of the questionnaire, which they filled in on a desktop computer or tablet. In order to prevent the skipping of items, it was only possible to end the digital questionnaire when all items were answered. When there were insufficient technical facilities at the school to administer the digital questionnaire, pupils filled in a paperand-pencil version. Several studies and meta-analyses with diverse populations and various questionnaires showed no effects of assessment mode (e.g., Gnambs and Kaspar 2017; Mangunkusumo et al. 2006). Classes with young pupils (age eight till ten) always received a paper-and-pencil version of the questionnaire, because in these classrooms, every question was read aloud by the research assistant.

\subsection{Data Analysis}

The criterion validity of the PASSI questionnaire was investigated through several phases of data analysis. Criterion validity requires that the questionnaire items produce empirical data that can be reliably interpreted based on the theory. This implies that the hypothesized subscales in the questionnaire are corroborated by the data: items that comprise a subscale should be highly correlated (convergent validity), while items from different subscales should not be highly correlated (discriminant validity). In the following, we describe in detail what methods we employed to establish and examine the criterion validity of the PASSI questionnaire.

\subsubsection{Content Analysis}

The two open questions were analyzed by automatic word count in "ATLAS.ti" and further categorization of the relevant words that occurred two times or more.

\subsubsection{Preliminary Data Checks}

First, we checked our quantitative dataset on missing data and investigated the variance of the individual items by assessing the range of responses and the standard deviation of respondents' scores. Next, we divided the dataset in two random subsamples of equal size $(n=685)$. This allows for cross-validation of an exploratory factor analysis (EFA) solution in a different dataset using confirmatory factor analysis (CFA) (Floyd and Widaman 1995). 


\subsubsection{Exploratory Factor Analysis}

Since the PASSI questionnaire was newly developed, based on a synthesis of different theoretical fields, we wanted to explore whether our hypothesized constructs could be distinguished as latent factors in the observed data. This is possible with EFA, because of its explorative and data-driven character. Using Mplus version 7.4 (Muthén and Muthén 2015), we performed iterative EFAs on subsample 1, using the option "Categorical" and weighted least squares estimation with means and variance adjusted (WLSMV). Geomin oblique rotation was used because we expected the subscales to correlate (Worthington and Whittaker 2006).

Models with 1 to 10 factors were investigated to determine the number of factors that fitted the data best. Considering high sensitivity of the $\chi 2$ statistic to large respondent groups, we examined multiple other goodness-of-fit indices to exploratively test the number of factors that fitted our data best: SRMR, RMSEA, CFI, and TLI (e.g., Prudon 2015; Worthington and Whittaker 2006). Eigenvalues were also checked. These should be above 1 to be considered more important than an observed variable (Worthington and Whittaker 2006). SRMR and RMSEA should be below .05 to indicate good fit, and CFI and TLI values should exceed .95 (Geiser 2013). It should be noted that these model fit threshold values are simply guidelines and should not be interpreted as strict rules (Prudon 2015). Therefore, in examining our EFA results, we not only focused on these indices but also on the content of our hypothesized factors. Following Prudon (2015), we computed the accuracy of prediction (AP) to explore what number of factors was best in line with our theory. AP can be seen as the proportion of items that are found to load mainly on its theoretically expected factor. We computed the average AP of the factor structures that the EFA provided.

The EFA also aided us with the removal of any problematic or redundant items from the questionnaire in preparation of the confirmatory factor analysis (CFA). That is, items were omitted from consecutive EFAs when they showed a factor loading lower than 40 or crossloadings less than a .15 difference from an item's greatest factor loading (Floyd and Widaman 1995; Worthington and Whittaker 2006). Before omitting these items, their content and formulation was critically examined.

\subsubsection{Confirmatory Factor Analysis}

Unlike EFA, CFA allows for testing how well the observed data fit a pre-defined factor structure. We performed CFA with WLSMV to assess how well the data of subsample 2 fitted the factorial structure that we derived from the EFA. As with the EFA, we examined RMSEA, CFI, and TLI to determine the model fit. Instead of SRMR, Mplus provides WRMR for CFA, which should be below 1.0 (Yu 2002). Moreover, factor loadings were examined.

\subsubsection{Convergent and Discriminant Validity}

To determine the convergent and discriminant validity of the subscales (Carter 2016), we followed the procedure of Fornell and Larcker (1981) to calculate the amount of shared variance among items that belong to a subscale (i.e., average variance extracted, AVE), and the shared variance between constructs (maximum shared variance, MSV, and average shared variance, ASV). The procedure of Raykov (1997) was used to calculate composite reliability (CR). Fornell and Larcker argued that convergent validity of a subscale is considered 
satisfactory when AVE is equal to or greater than .50, and the CR value of a subscale is greater than the AVE value of the subscale. In addition, the $C R$ value should be equal to or greater than .70 (Molina et al. 2007). Discriminant validity of a subscale is met when the AVE of the subscale is greater than its MSV and greater than its ASV (Fornell and Larcker 1981).

\subsubsection{Measurement Invariance}

To test the ability of the PASSI questionnaire to make fair comparisons between the attitude scores of pupils in primary and secondary education and of pupils in different secondary educational tracks, we tested the three most common assumptions of measurement invariance: configural, metric, and scalar invariance (Putnick and Bornstein 2016; Vandenberg and Lance 2000). As our primary tests of measurement invariance, we examined differences between the configural model and the metric and scalar model in CFI and $\chi 2$, where a $\Delta$ CFI less than or equal to .01 and non-significant $p$ values ( $>.05$ ) for the $\Delta \chi 2$ indicate invariance (Cheung and Rensvold 2002).

\section{Results}

\subsection{Content Analysis}

The ten world issues that pupils most frequently named are (in descending order) war $(n=$ 837), pollution, water issues, refugees, global warming, exhaust gasses, poverty, natural disasters, disease, and deforestation $(n=237)$. According to the pupils, the professions or actors that are needed to solve the issues are (in descending order) scientists $(n=585)$, inventors, techies, governments, soldiers, doctors, environmentalists, charities, police, and volunteers $(n=35)$. These results suggest that pupils indeed interpret world issues as those issues that reflect the interplay between societal issues and technological or scientific developments and that this term sufficiently represents the meaning of SSI.

\subsection{Preliminary Data Checks}

Both EFA and CFA were performed with the raw data, including missing data (which was $0.09 \%$ ) using maximum likelihood estimation in Mplus. We examined the variance of each item by computing the standard deviation and range of responses. The standard deviations ranged between .67 and .86 , and all response options were used at least once, indicating a sufficient spread of responses (Coulson 1992). The data were thus considered adequate for subsequent factor analyses.

\subsection{Exploratory Factor Analysis}

The EFA and CFA were conducted with two different subsamples of the data that were extracted from the total respondent group through simple random sampling. We conducted iterative EFAs with subsample 1 to investigate the latent factor structure. The results were not straightforward about the number of factors that could be derived from the data. The eigenvalues pointed to an 8-factor structure, while SRMR, CFI, TLI, and RMSEA also suggested a 7-factor solution to show good model fit, and the formula of Prudon (2015) for 
AP suggested a 9-factor solution to be best in line with our theory. See Table 2 for goodnessof-fit values and AP for the 6-, 7-, 8-, and 9-factor structures.

Although reasons of parsimony are important to consider, we initially decided to proceed with the 9-factor structure, because it was best in line with our theory and showed good fit with the data. Subsequently, items were omitted from consecutive EFAs when they showed a factor loading lower than .40 or cross-loadings less than a .15 difference from an item's greatest factor loading (Floyd and Widaman 1995; Worthington and Whittaker 2006). After several EFA iterations, 10 items were removed from the questionnaire, leaving a total of 38 items and 8 factors. The observed factor structure had 8 factors instead of our initially hypothesized 9factor structure, because, in the second iteration, the remaining items of the subscale Relevance of Science and Technology showed high cross-loadings with the subscale Relevance of Institutions. Based on the size of the factor loadings, we removed all items that were originally developed for the Relevance of Science and Technology factor, while we kept the items for the subscale Relevance of Institutions.

After the above-described data reduction, we decided to reduce the number of items even further, since we wanted to construct a parsimonious measurement instrument with around three items per subscale. Thus, although not necessary from a statistical perspective, we critically reconsidered the remaining items for each subscale and decided to remove eleven more items, based on conceptual or semantic reasons (e.g., redundancy, clear wording). Finally, with the factor structure obtained by the EFA and our decision to remove additional items, we derived 8 subscales with a total of 27 items (see Table 3).

\subsection{Confirmatory Factor Analysis}

We performed CFA to assess how well the data of subsample 2 fitted the obtained factorial structure as derived by EFA, based on our final solution with 27 items. The CFA confirmed good model fit of the 8-factor structure of the PASSI instrument $($ WRMR $=.97$, RMSEA $=$ $.04, \mathrm{TLI}=.98, \mathrm{CFI}=.98$ ). See Table 3 for the factor structure and factor loadings as obtained by CFA.

\subsection{Convergent and Discriminant Validity}

Convergent and discriminant validity were checked with the data from subsample 2. All interfactor correlations were positive, but several factor correlations were relatively high (see

Table 2 Goodness of fit indices and accuracy of prediction in terms of number of items (AP) for the 6-, 7-, 8-, and 9-factor structures as obtained by EFA (subsample 1)

\begin{tabular}{llllll}
\hline$n$ factors & SRMR & RMSEA & CFI & TLI & APb \\
\hline 6 & .04 & $.06^{\mathrm{a}}$ & .95 & $.94^{\mathrm{a}}$ & .73 \\
7 & .03 & .05 & .97 & .95 & .72 \\
8 & .03 & .04 & .98 & .96 & .82 \\
9 & .02 & .04 & .98 & .97 & .95 \\
\hline
\end{tabular}

a Not sufficient according to cutoff values $($ SRMR $<.05$, RMSEA $<.05$, CFI $>.95$, TLI $>.95)$

${ }^{\mathrm{b}} \mathrm{AP}$ is computed with the number of hits (items that were predicted as indicators of a factor and found mainly loading on that factor), the number of items that were predicted as indicators but not found as such, and the number of items that were not predicted as indicators but were found as such (Prudon 2015). Factor loadings were used as weights 


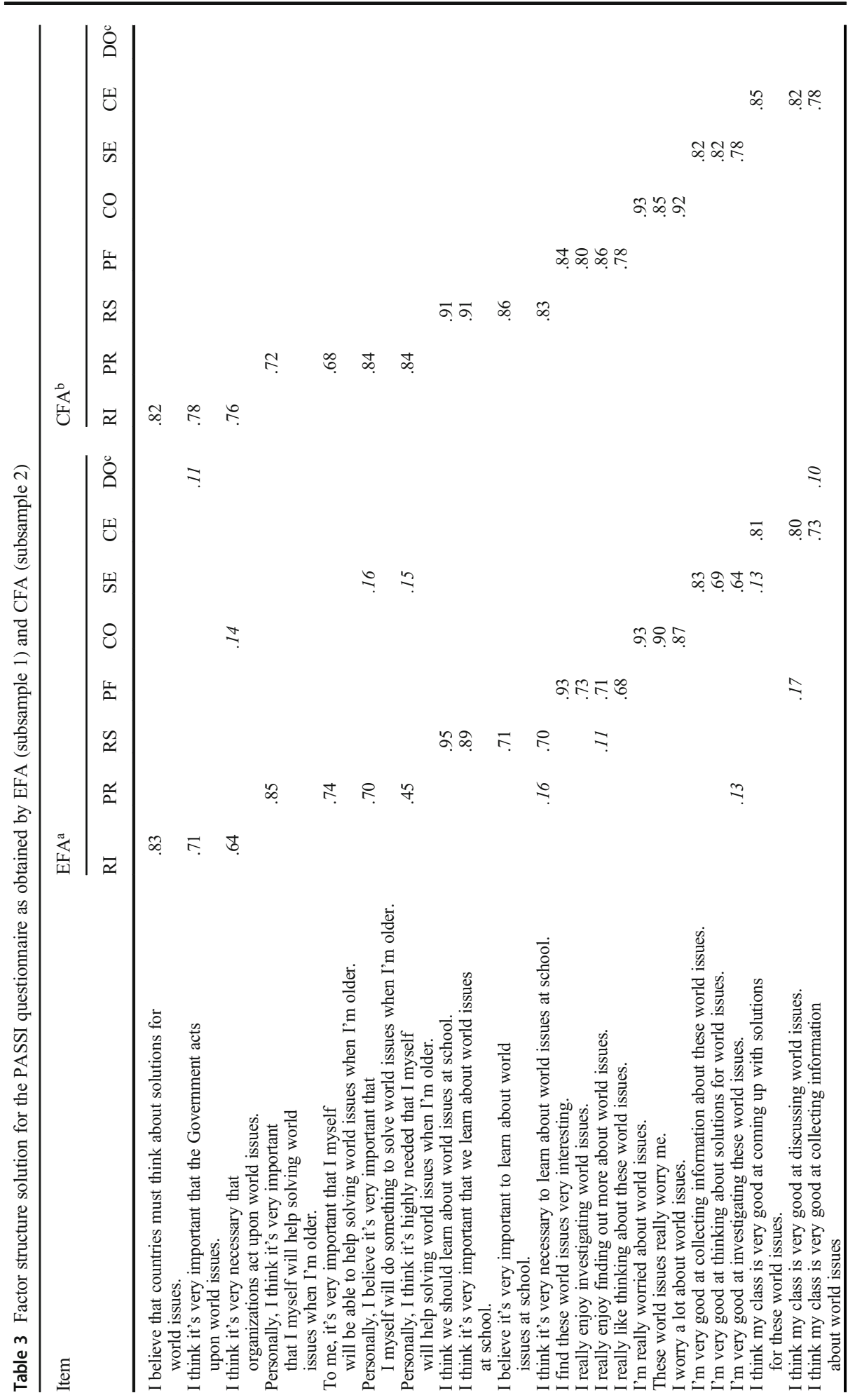




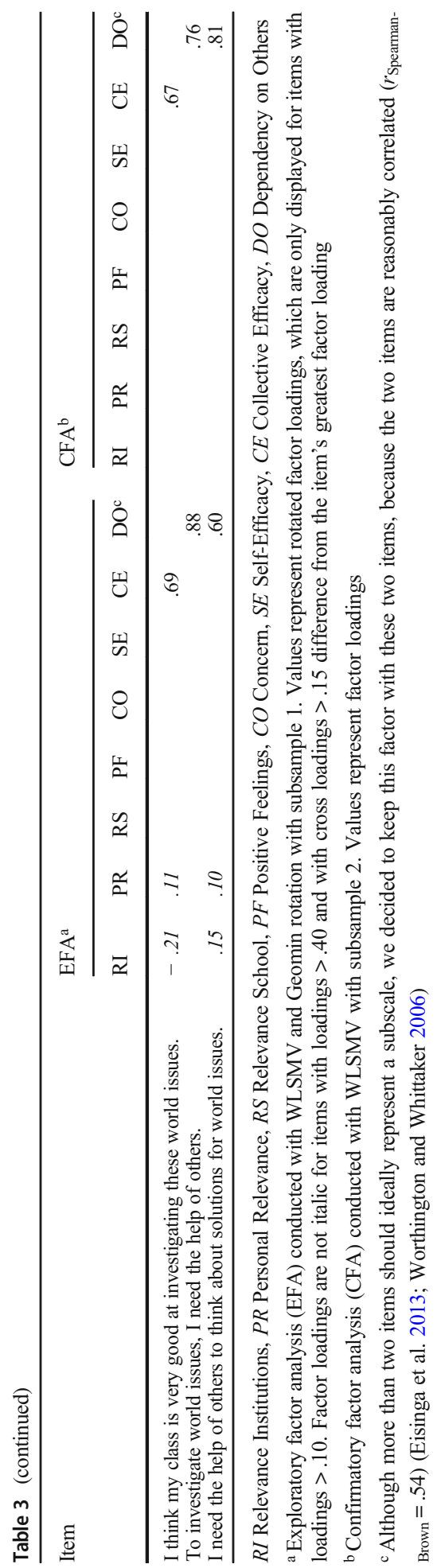


Table 4). Nevertheless, both EFA and CFA showed clearly distinguishable factors, and the discriminant power of the subscales was found to be sufficient, as indicated by AVE values that exceeded MSV and ASV. In addition, AVE values exceeded .50, and CR values exceeded the threshold value of .70, as well as the AVE values for each respective subscale, indicating good convergent validity of the subscales.

\subsection{Measurement Invariance}

A multiple group CFA on the total respondent sample was conducted to test measurement invariance of the PASSI questionnaire across groups of primary $(n=382)$ and secondary $(n=$ 988 ) education, within secondary education across groups of pupils in pre-vocational $(n=255)$ and pre-university $(n=733)$ education, ${ }^{3}$ and across boys $(n=660)$ and girls $(n=710)$.

As presented in Table 5, for all our measurement invariance tests, the model fit of the configural model was very good. Although WRMR was larger than 1, all other fit indices suggest that the different groups of pupils associated the same subsets of items with the same constructs. For all metric models, compared to the configural models, $\Delta$ CFI did not exceed .01, and the $p$ values for $\Delta \chi 2$ were non-significant, which suggests that, apart from equivalence in factor structure, we also found factor loadings to be equal across our different respondent groups. These results suggest that the PASSI questionnaire measures the same constructs the same way for our different respondent groups and may be used to compare the attitude scores of primary and secondary pupils, of pupils in pre-vocational and pre-university secondary education, and of boys and girls.

However, when we also applied the most stringent invariance test (scalar invariance) and held the item intercepts equal across groups, we found that for primary versus secondary pupils scalar invariance could not be completely corroborated, $\Delta \chi 2(65)=88.35, p=.029$. Nevertheless, as listed in Table 5, the CFI difference for this comparison was less than .01, suggesting scalar invariance to hold. For the comparison between pupils in pre-vocational and preuniversity secondary education and boys and girls, scalar invariance was verified for all indices.

\subsection{Group Comparisons}

Although our main goal was to statistically validate the PASSI instrument, we also investigated some overall differences between subgroups in our sample. Since we did not have any theoretical reasons to suspect particular differences between subgroups, this cannot be interpreted as a measure of concurrent validity but should be seen as a further exploration of the data. Table 6 shows means and standard deviations per subgroup and $t$ tests with a Bonferroni corrected alpha of .006. These $t$ tests show several differences between pupils in pre-vocational and in pre-university secondary education. Overall, pupils in pre-university secondary education reported higher beliefs of the relevance of institutions in solving SSI $(d=.37)$, more positive feelings $(d=.26)$, more concerns about SSI $(d=.28)$, and more selfefficacy in being engaged with SSI $(d=.23)$. Pupils in primary and secondary education did not differ in their mean attitudes towards SSI. Girls and boys did differ: girls found institutions more relevant in solving SSI $(d=.16)$ and reported to be more concerned about SSI than boys

\footnotetext{
${ }^{3}$ The general educational track "HAVO" is included in the pre-university group. See De Groot (2013) for an explanation of the Dutch school system.
} 


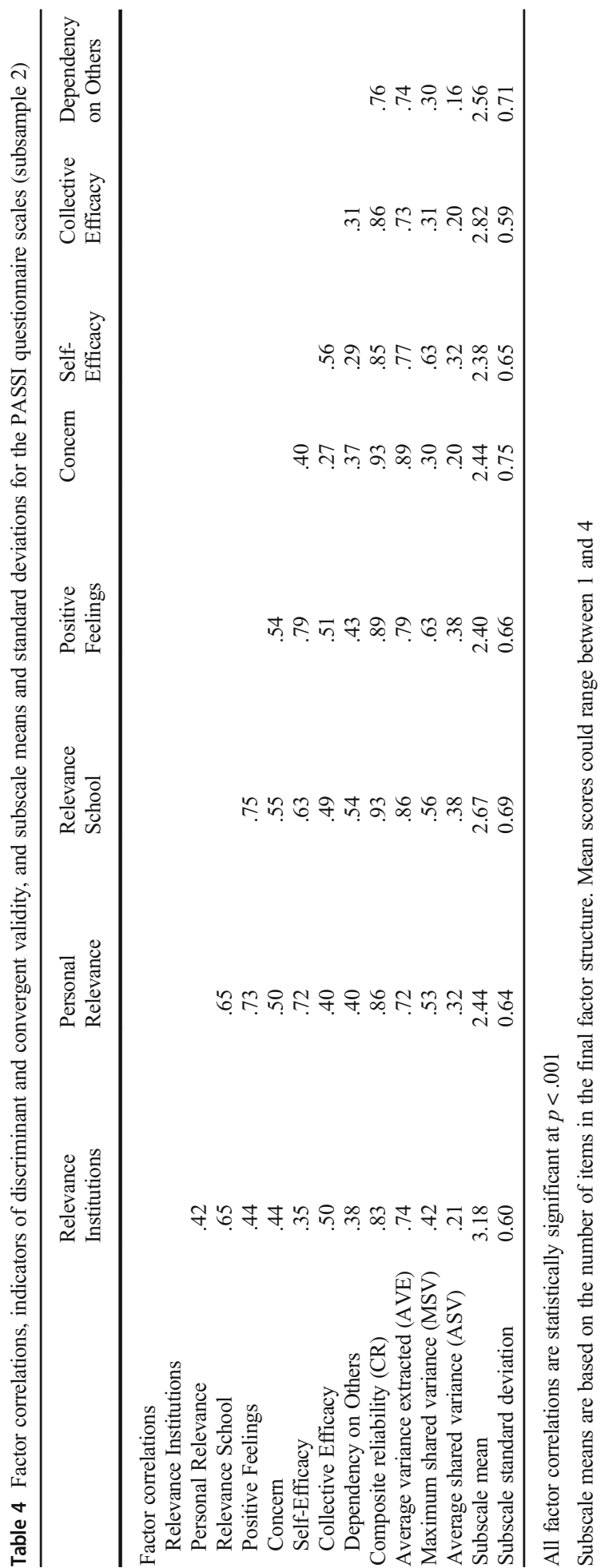


Table 5 Measurement invariance results of the PASSI questionnaire, with educational level, secondary educational track, and gender as group comparisons (total sample)

\begin{tabular}{|c|c|c|c|c|c|c|c|c|c|c|}
\hline & $\chi^{2}$ & $d f$ & WRMR & RMSEA & TLI & CFI & $\Delta \mathrm{CFI}$ & $\Delta \chi^{2}$ & $\Delta d f$ & $p$ \\
\hline \multicolumn{11}{|c|}{ Primary versus secondary educational level } \\
\hline Configural & 1330.35 & 592 & $1.42^{\mathrm{a}}$ & .04 & .98 & .99 & & & & \\
\hline Metric & 1321.84 & 611 & $1.43^{\mathrm{a}}$ & .04 & .96 & .99 & $<.01$ & 21.73 & 19 & .298 \\
\hline Scalar & 1364.05 & 657 & $1.48^{\mathrm{a}}$ & .04 & .99 & .99 & $<.01$ & 88.35 & 65 & $.029^{\mathrm{a}}$ \\
\hline \multicolumn{11}{|c|}{ Pre-vocational versus pre-university secondary educational track } \\
\hline Configural & 1293.37 & 592 & $1.36^{\mathrm{a}}$ & .05 & .98 & .98 & & & & \\
\hline Metric & 1293.41 & 611 & $1.37^{\mathrm{a}}$ & .05 & .98 & .98 & $<.01$ & 22.67 & 19 & .253 \\
\hline Scalar & 1315.67 & 657 & $1.41^{\mathrm{a}}$ & .05 & .98 & .99 & $<.01$ & 83.43 & 65 & .062 \\
\hline \multicolumn{11}{|c|}{ Boys versus girls } \\
\hline Configural & 1303.64 & 592 & $1.34^{\mathrm{a}}$ & .04 & .98 & .99 & & & & \\
\hline Metric & 1305.80 & 611 & $1.36^{\mathrm{a}}$ & .04 & .98 & .99 & $<.01$ & 21.11 & 19 & .253 \\
\hline Scalar & 1344.97 & 657 & $1.39^{\mathrm{a}}$ & .04 & .99 & .99 & $<.01$ & 61.24 & 46 & .066 \\
\hline
\end{tabular}

Models are compared using the chi-square difference test for nested models in Mplus

${ }^{a}$ Not sufficient according to cutoff values (WRMR $<1.0$, RMSEA $<.05$, TLI $>.95$, CFI $>.95, \Delta$ CFI $<.01, \Delta \chi^{2}$ non-significant at $p>.05$ )

$(d=.05)$. Note that the effect sizes of gender differences are small, and differences between secondary educational tracks have small to medium effect sizes (Cohen 1988).

\section{Discussion and Conclusions}

This study focused on the development and validation of a questionnaire to measure pupils' attitudes towards SSI. To the best of our knowledge, the development of the PASSI is the first attempt to measure these aspects in pupils aged eight to fifteen. Decades of social psychological research show that attitudes are important precursors to behavioral and cognitive engagement (e.g., Ajzen and Fishbein 1980, 2005; Eagly and Chaiken 1993). In line with this research, we expect that a fruitful approach to stimulating pupils' engagement with SSI is to foster their concerns about SSI and positive beliefs and feelings about engagement with SSI.

Students' engagement with SSI can be researched with quantitative, qualitative, or mixed methods. To make quantitative research as reliable and valid as possible, elaborate psychometric validation of measurement instruments is of the utmost importance, especially with complex constructs such as engagement or attitudes. To ensure translation validity, we based the constructs of the PASSI questionnaire on a wide range of literature. We pilot tested the questionnaire and checked pupils' interpretation of world issues. Criterion validity was extensively investigated, with exploratory and confirmatory factor analysis on two random subsamples. Moreover, the results of measurement invariance tests corroborated the quality of the questionnaire and the usability for group comparisons. We believe that the PASSI questionnaire is an important addition to research into SSI education, as a validated measurement instrument for quantitative research that could complement qualitative research.

\subsection{Main Findings}

The EFA provided a factor structure with eight clearly distinguishable factors that were replicated with another subsample in the CFA. In addition, we supplemented conventional 


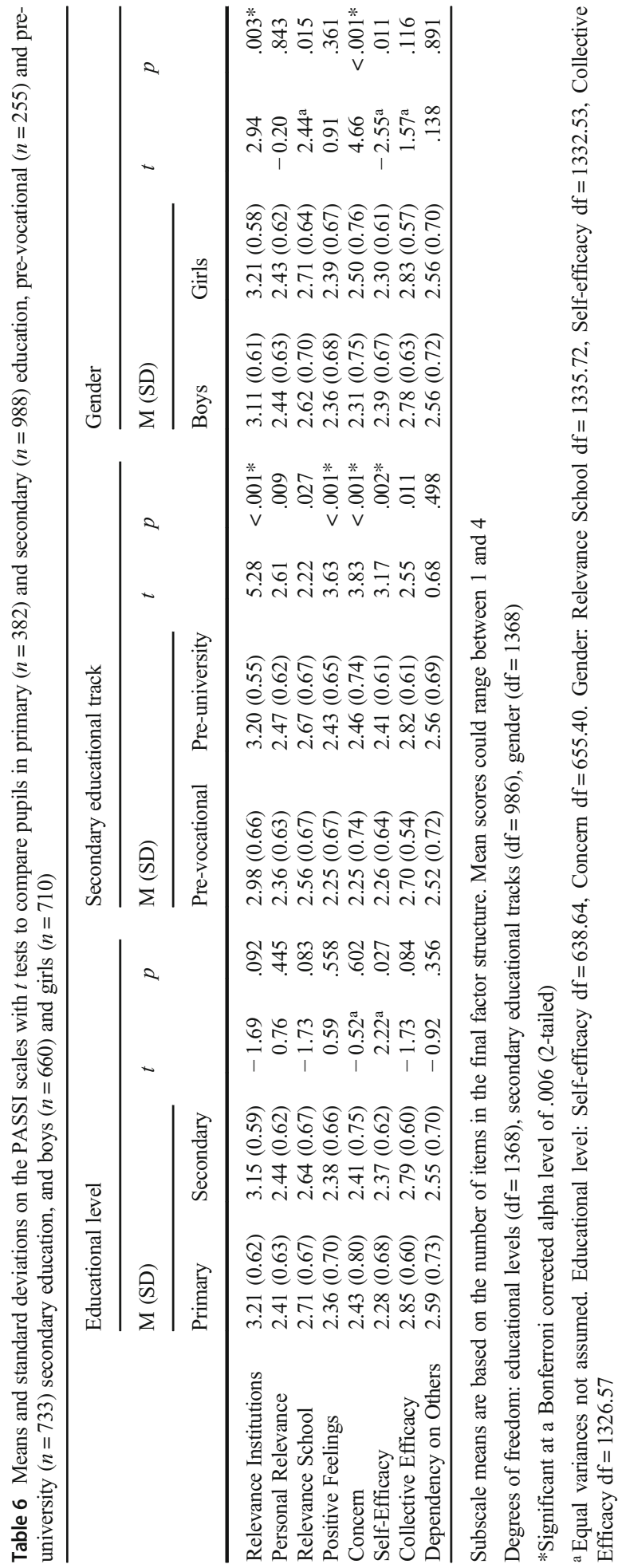


factor-analytic measurements with calculations of the convergent and discriminant power of the PASSI subscales (Carter 2016; Fornell and Larcker 1981). The subscales showed discriminant power as well as convergent validity.

Three of the PASSI subscales are about relevance. The inter-factor correlations between these scales were positive, as could be expected because all three scales were designed to be indicative of engagement with SSI. Two subscales are about affect: positive feelings and concern. Although concern seems a negative affect and a positive correlation with positive feelings may seem odd, it is important to note that this scale in the PASSI questionnaire is meant to measure engagement with SSI, and, in this light, concern about SSI as well as positive feelings can be signs of engagement with SSI.

Three subscales of the PASSI are about perceived control. Dependency on others was positively correlated with self-efficacy and collective efficacy. However, the scale dependency on others was developed to be a negative indicator of engagement with SSI. Although these correlations were relatively low, this finding raises questions about the validity of this subscale. It could be that this subscale actually measures pupils' beliefs about the complexity of SSI (Kahn and Zeidler 2019). Compare, for example, to one of the items of the attitude towards decision-making scale from Chang et al. (2018): "There is a need to consider multiple perspectives to make the decision." Another reason for the positive correlations could be method bias. A multitrait-multimethod design would be necessary to investigate this (Muis et al. 2007).

Finally, because we intend to use the PASSI to measure pupils' attitudes towards SSI over time and across educational tracks, we also assessed measurement invariance (Putnick and Bornstein 2016; Vandenberg and Lance 2000). The PASSI questionnaire was found to be able to fairly compare attitudes of pupils in pre-vocational and pre-university secondary education and across boys and girls. This confirms the quality of the PASSI questionnaire. However, the results were not conclusive about scalar measurement invariance (a stringent form of measurement invariance) across pupils in primary and secondary education. Therefore, we conclude that the PASSI may be used to compare pupils in pre-vocational and pre-university secondary education, and across boys and girls, but that comparisons between pupils in primary and secondary education must be done cautiously (Cheung and Rensvold 2002).

Pupils in primary and secondary education did not seem to differ in their attitudes towards SSI. Pupils in pre-university secondary education were found to believe it more important that institutions should act towards solving SSI than pupils in pre-vocational education. Also, positive feelings and self-efficacy were found to be more positive among pupils in preuniversity education, and they were more concerned about SSI. Note that the Bonferroni correction can be too severe (Cohen 1990) and it is possible that these pupils also differ on the other subscales (except on dependency on others).

Overall, pupils' attitudes towards SSI were not high, but also not extremely low. Similar results were found in a study about adolescents' environmental attitudes (Wray-Lake et al. 2010), and in international measures of interest in social and political issues, political selfefficacy, and citizenship self-efficacy among pupils who were approximately 14 years old (Schulz et al. 2010, pp. 279-281). SSI education could possibly influence pupils' attitudes towards SSI. However, evidence of influences of SSI teaching and learning on attitudes towards SSI is lacking. In future studies, we will therefore use the PASSI questionnaire to investigate effects of SSI education on pupils' attitudes towards SSI. Moreover, it is interesting to investigate if pupils score higher on the different subscales of the PASSI when world issues are translated to concrete issues that relate to pupils' own environment (e.g., personal use of 
plastic). Although this is a different attitude object, we believe that the PASSI scales could be adapted to measure these attitudes as well.

\subsection{Directions for Future Research}

Although our analyses show the PASSI questionnaire to be a viable instrument for measuring pupils' attitudes towards SSI, a few things could be improved. First, the subscale dependency on others now consists of two items, and questions were raised about the validity of this scale. Collective efficacy and self-efficacy (as positive indicators) seem to be better measures of perceived control.

Second, although the initial nine scales were based on a wide range of literature, it could be that our framework does not describe all important attitudes that are indicative of pupils' engagement with SSI. In hindsight, we argue that stimulating others to act towards solving SSI is an aspect of engagement with SSI that is missing in our questionnaire. Several studies showed that this is a way in which adolescents act upon SSI (Connell et al. 2014; Stenseth et al. 2016; Vesterinen et al. 2016). Further research could consider adding items such as "I believe it's very important that I try to convince others to help solve world issues" to the questionnaire. It is unclear from the literature if this should be a different subscale or an aspect of the personal relevance scale. Further research could clarify this.

Third, the scale about the relevance of science and technology in solving SSI was empirically not distinguishable. This could be due to semantic reasons, where the solution would lie in another choice of words. The reason we did not find evidence for our relevance of science and technology factor could also be that pupils are not able to separate science and technology from institutions, but view these together as the relevance of "other people" (two of the five science and technology items were about scientists). That is, the items that were developed for the relevance of science and technology scale cross-loaded on the relevance of institutions factor. Future research could investigate whether pupils who received education about the role of science and technology in SSI or who have more socioscientific capital available in their home or social environment do separate science and technology from institutions.

In addition to these suggestions for improvement of the PASSI questionnaire, there are also more general directions for further research. First, although we validated the PASSI questionnaire extensively, the investigation of predictive validity was not part of our study. The PASSI questionnaire measures attitudes that may predict behavioral and cognitive engagement with SSI. Following the TPB, the combination of attitudes, perceived control, and subjective norms should be able to predict the intention to engage with SSI (Ajzen 1991). Pupils who are concerned about SSI and have positive beliefs and feelings about engagement with SSI might be more inclined to discuss, investigate, or solve SSI and think, worry, or learn about SSI. Investigating the predictive power of the PASSI questionnaire is not only important as an indicator of criterion validity. Insight in the extent to which pupils' attitudes towards SSI indeed predict pupils' engagement with SSI is also important to demonstrate the importance of pupils' attitudes and the utility of the PASSI questionnaire. Therefore, the predictive validity of the PASSI should be investigated in future research.

Second, for the development of the PASSI questionnaire, we theoretically conceptualized attitudes as a tendency. However, there is no consensus on this feature of attitudes. Instead of a tendency, attitudes can also be more extremely defined as stable entities stored in memory or as temporary judgments constructed on the spot (Bohner and Dickel 2011). Whether a more 
stable entity or constructionist view is held has important consequences for views on attitude change and attitude-behavior relations (Bohner and Dickel 2011; Eagly and Chaiken 2007), and therefore for the utility of the PASSI questionnaire. However, as Schwarz (2007) argued, there is no empirical answer to the question if attitudes are stable entities or temporary judgments. Taking an intermediate view of attitudes as a tendency, we believe that attitudes measured with the PASSI questionnaire are reasonably stable but malleable. This means that the questionnaire can be used to gain insight into pupils' attitudes and to assess attitude change after educational interventions. Such longitudinal intervention studies as well as investigation of the test-retest reliability of the PASSI questionnaire could provide more insight in the stability and/or situational variability of pupils' attitudes towards SSI.

Another general direction for future research is to validate the English version of the PASSI questionnaire. The eight subscales were originally constructed in Dutch. We translated them as well as possible, but this must be done more thoroughly. Then, the PASSI scales can be validated in an educational setting with an English-speaking sample.

\subsection{Conclusions}

Our PASSI questionnaire validly measures eight attitudes towards SSI of boys and girls in primary and secondary education and at different secondary educational tracks. It can be used with large samples to investigate the effects of educational interventions, to compare groups, and to develop profiles. That is, scores on the different subscales may provide "profiles" of pupils who hold different combinations of scores on the separate attitude components. This kind of research can support the quality of SSI education. Intervention studies and knowledge about attitudes towards SSI can guide the development of learning activities. Teachers can use pupils' attitude profiles diagnostically and adapt their teaching accordingly. To conclude, for citizens to engage with SSI and develop a functional kind of scientific literacy, SSI should already receive attention in primary and secondary education. The PASSI could serve as a tool that raises awareness of pupils' engagement with SSI and of the importance of SSI in education.

Acknowledgments We would like to thank Kim Evers and Dr. Tim Post for their contributions to the research reported.

Authors' Contributions Both authors contributed to the study conception and design. Material preparation, data collection, and analysis were performed by Klaver and Walma van der Molen. The first draft of the manuscript was written by Klaver, and all authors commented on previous versions of the manuscript. All authors read and approved the final manuscript.

Funding TechYourFuture, center of expertise in technology education, funded the research reported in the manuscript.

Data Availability Data, material, and code are available upon request.

\section{Compliance with Ethical Standards}

Conflict of Interest The authors declare that they have no conflict of interest. 


\section{References}

Ainley, M., \& Ainley, J. (2011). Student engagement with science in early adolescence: The contribution of enjoyment to students' continuing interest in learning about science. Contemporary Educational Psychology. https://doi.org/10.1016/j.cedpsych.2010.08.001.

Ajzen, I. (1985). From intentions to actions: A theory of planned behavior. In J. Kuhl \& J. Beckmann (Eds.), Action-control: From cognition to behavior (pp. 11-39). https://doi.org/10.1007/978-3-642-69746-32.

Ajzen, I. (1991). The theory of planned behavior. Organizational Behavior and Human Decision Processes. https://doi.org/10.1016/0749-5978(91)90020-T.

Ajzen, I. (2001). Nature and operation of attitudes. Annual Review of Psychology. https://doi.org/10.1146 /annurev.psych.52.1.27.

Ajzen, I. (2002). Perceived behavioral control, self-efficacy, locus of control, and the theory of planned behavior. Journal of Applied Social Psychology. https://doi.org/10.1111/j.1559-1816.2002.tb00236.x.

Ajzen, I. (2011). The theory of planned behaviour: Reactions and reflections. Psychology \& Health. https://doi. org/10.1080/08870446.2011.613995.

Ajzen, I., \& Driver, B. L. (1991). Prediction of leisure participation from behavioral, normative, and control beliefs: An application of the theory of planned behavior. Leisure Sciences. https://doi.org/10.1080 /01490409109513137.

Ajzen, I., \& Fishbein, M. (1980). Understanding attitudes and predicting social behavior. Upper Saddle River: Prentice-Hall.

Ajzen, I., \& Fishbein, M. (2005). The influence of attitudes on behavior. In D. Albarracín, B. T. Johnson, \& M. P. Zanna (Eds.), The handbook of attitudes (pp. 173-221). https://doi.org/10.4324/9781410612823.

Albarracin, D., \& Shavitt, S. (2018). Attitudes and attitude change. Annual Review of Psychology. https://doi. org/10.1146/annurev-psych-122216-011911.

Asma, L., Walma van der Molen, J. H., \& Van Aalderen-Smeets, S. I. (2011). Primary teachers' attitudes towards science and technology. In M. J. De Vries, H. Van Keulen, S. Peters, \& J. Walma van der Molen (Eds.), Professional development for primary teachers in science and technology (pp. 1-18). Rotterdam: Sense Publisher.

Azevedo, R. (2015). Defining and measuring engagement and learning in science: Conceptual, theoretical, methodological, and analytical issues. Educational Psychologist. https://doi.org/10.1080 $/ 00461520.2015 .1004069$.

Bandelli, A., \& Konijn, E. A. (2015). Public participation and scientific citizenship in the science museum in London: Visitors' perceptions of the museum as a broker. Visitor Studies. https://doi.org/10.1080 /10645578.2015.1079089.

Bandura, A. (2000). Exercise of human agency through collective efficacy. Current Directions in Psychological Science. https://doi.org/10.1111/1467-8721.00064.

Bandura, A. (2006). Guide for constructing self-efficacy scales. In F. Pajares \& T. Urdan (Eds.), Self-efficacy beliefs of adolescents (pp. 307-337). Charlotte: Information Age.

Barratt Hacking, E., Barratt, R., \& Scott, W. (2007). Engaging children: Research issues around participation and environmental learning. Environmental Education Research. https://doi.org/10.1080/13504620701600271.

Bauer, M. W., Shukla, R., \& Allum, N. (2012). The culture of science. How the public relates to science across the globe. https://doi.org/10.4324/9780203813621.

Bencze, L., Sperling, E., \& Carter, L. (2012). Students' research-informed socio-scientific activism: Re/visions for a sustainable future. Research in Science Education. https://doi.org/10.1007/s11165-011-9260-3.

Blalock, C. L., Lichtenstein, M. J., Owen, S., Pruski, L., Marshall, C., \& Toepperwein, M. (2008). In pursuit of validity: A comprehensive review of science attitude instruments 1935-2005. International Journal of Science Education. https://doi.org/10.1080/09500690701344578.

Bohner, G., \& Dickel, N. (2011). Attitudes and attitude change. Annual Review of Psychology. https://doi. org/10.1146/annurev.psych.121208.131609.

Boone, H. N., \& Boone, D. A. (2012). Analyzing Likert data. Journal of Extension, 50, 1-5 Retrieved from https://www.joe.org/joe/2012april/tt2.php.

Burek, K., \& Zeidler, D. L. (2015). Seeing the forest for the trees! Conservation and activism through socioscientific issues. In M. P. Mueller \& D. J. Tippins (Eds.), EcoJustice, citizen science and youth activism (pp. 425-441). https://doi.org/10.1007/978-3-319-11608-2_26.

Carter, S. R. (2016). Using confirmatory factor analysis to manage discriminant validity issues in social pharmacy research. International Journal of Clinical Pharmacy. https://doi.org/10.1007/s11096-016-0302-9.

Chang, H.-Y., Hsu, Y.-S., Wu, H.-K., \& Tsai, C.-C. (2018). Students' development of socio-scientific reasoning in a mobile augmented reality learning environment. International Journal of Science Education. https://oi. org/10.1080/09500693.2018.1480075. 
Cheung, G. W., \& Rensvold, R. B. (2002). Evaluating goodness-of-fit indexes for testing measurement invariance. Structural Equation Modeling: A Multidisciplinary Journal. https://doi.org/10.1207/S15328007 SEM0902 5.

Cohen, J. (1988). Statistical power analysis for the behavioral sciences. Second edition. https://doi.org/10.4324 19780203771587.

Cohen, J. (1990). Things I have learned (so far). The American Psychologist. https://doi.org/10.1037/0003-066 X.45.12.1304.

Connell, S., Fien, J., Lee, J., Sykes, H., \& Yencken, D. (1999). If it doesn’t directly affect you, you don't think about it': A qualitative study of young people's environmental attitudes in two Australian cities. Environmental Education Research. https://doi.org/10.1080/1350462990050106.

Connell, S., Fien, J., Sykes, H., \& Yencken, D. (2014). Young people and the environment in Australia: Beliefs, knowledge, commitment and educational implications. Australian Journal of Environmental Education. https://doi.org/10.1017/aee.2014.28.

Coulson, R. (1992). Development of an instrument for measuring attitudes of early childhood educators towards science. Research in Science Education. https://doi.org/10.1007/BF02356884.

De Groot, I. (2013). Adolescents' democratic engagement. Utrecht: Author.

Eagly, A. H., \& Chaiken, S. (1993). The psychology of attitudes. Fort Worth: Harcourt Brace Jovanovich.

Eagly, A. H., \& Chaiken, S. (2007). The advantages of an inclusive definition of attitude. Social Cognition. https://doi.org/10.1521/soco.2007.25.5.582.

Eisinga, R., Te Grotenhuis, M., \& Pelzer, B. (2013). The reliability of a two-item scale: Pearson, Cronbach, or Spearman-Brown? International Journal of Public Health. https://doi.org/10.1007/s00038-012-0416-3.

Ekborg, M., Ottander, C., Silfver, E., \& Simon, S. (2013). Teachers' experience of working with socio-scientific issues: A large scale and in depth study. Research in Science Education. https://doi.org/10.1007/s11165011-9279-5.

Elam, M., \& Bertilsson, M. (2003). Consuming, engaging and confronting science: The emerging dimensions of scientific citizenship. European Journal of Social Theory. https://doi.org/10.1177/1368431003006002005.

Feinstein, N. W. (2015). Education, communication, and science in the public sphere. Journal of Research in Science Teaching. https://doi.org/10.1002/tea.21192.

Floyd, F. J., \& Widaman, K. F. (1995). Factor analysis in the development and refinement of clinical assessment instruments. Psychological Assessment. https://doi.org/10.1037/1040-3590.7.3.286.

Fornell, C., \& Larcker, D. F. (1981). Evaluating structural equation models with unobservable variables and measurement error. Journal of Marketing Research. https://doi.org/10.2307/3151312.

Fredricks, J. A., Blumenfeld, P. C., \& Paris, A. H. (2004). School engagement: Potential of the concept, state of the evidence. Review of Educational Research. https://doi.org/10.3102/00346543074001059.

Geiser, C. (2013). Data analysis with Mplus. New York: The Guilford Press.

Gnambs T, Kaspar K (2017) Socially desirable responding in web-based questionnaires: A meta-analytic review of the candor hypothesis. Assessment, https://doi.org/10.1177/1073191115624547

Guérin, L. J. F. (2018). Group problem solving as citizenship education. Mainstream idea of participation revisited. Deventer: Saxion Progressive Education University Press.

Hancock, T. S., Friedrichsen, P. J., Kinslow, A. T., \& Sadler, T. D. (2019). Selecting socio-scientific issues for teaching: A grounded theory study of how science teachers collaboratively design SSI-based curricula. Science \& Education. https://doi.org/10.1007/s11191-019-00065-x.

Hicks, D., \& Holden, C. (2007). Remembering the future: What do children think? Environmental Education Research. https://doi.org/10.1080/13504620701581596.

Hodson, D. (2003). Time for action: Science education for an alternative future. International Journal of Science Education. https://doi.org/10.1080/09500690305021.

Hodson, D. (2006). Why we should prioritize learning about science. Canadian Journal of Science, Mathematics, and Technology Education. https://doi.org/10.1080/14926150609556703.

Irwin, A. (2001). Constructing the scientific citizen: Science and democracy in the biosciences. Public Understanding of Science. https://doi.org/10.1088/0963-6625/10/1/301.

Johns, R. (2010). Likert items and scales. Retrieved from https://ukdataservice.ac.uk/media/262829/discover_ likertfactsheet.pdf

Kahn, S., \& Zeidler, D. L. (2019). A conceptual analysis of perspective taking in support of socioscientific reasoning. Science \& Education. https://doi.org/10.1007/s11191-019-00044-2.

Kim, H.-S. (2012). Measuring PEP/IS, a new model for communicative effectiveness of science. In M. W. Bauer, R. Shukla, \& N. Allum (Eds.), The culture of science. How the public relates to science across the globe (pp. 375-384). New York: Routledge.

Kolstø, S. D. (2001). Scientific literacy for citizenship: Tools for dealing with the science dimension of controversial socioscientific issues. Science Education. https://doi.org/10.1002/sce.1011. 
Krosnick, J. A. (2018). Improving question design to maximize reliability and validity. In D. L. Vannette \& J. A. Krosnick (Eds.), The Palgrave handbook of survey research (pp. 95-101). https://doi.org/10.1007/978-3319-54395-6 13.

Kulas, J. T., \& Stachowski, A. A. (2009). Middle category endorsement in odd-numbered Likert response scales: Associated item characteristics, cognitive demands, and preferred meanings. Journal of Research in Personality. https://doi.org/10.1016/j.jrp.2008.12.005.

Kulas, J. T., Stachowski, A. A., \& Haynes, B. A. (2008). Middle response functioning in Likert-responses to personality items. Journal of Business and Psychology. https://doi.org/10.1007/s10869-008-9064-2.

Lee, H., Abd-El-Khalick, F., \& Choi, K. (2006). Korean science teachers' perceptions of the introduction of socio-scientific issues into the science curriculum. Canadian Journal of Science, Mathematics, and Technology Education. https://doi.org/10.1080/14926150609556691.

Levinson, R., Knippels, M. C., Van Dam, F., Kyza, E., Christodoulou, A., et al. (2017). Science and society in education. Utrecht: PARRISE.

Littledyke, M. (2004). Primary children's views on science and environmental issues: Examples of environmental cognitive and moral development. Environmental Education Research. https://doi.org/10.1080 $/ 13504620242000198186$.

Mangunkusumo, R. T., Duisterhout, J. S., De Graaff, N., Maarsingh, E. J., De Koning, H. J., \& Raat, H. (2006). Internet versus paper mode of health and health behavior questionnaires in elementary schools: Asthma and fruit as examples. The Journal of School Health. https://doi.org/10.1111/j.1746-1561.2006.00072.x.

McIntosh, H., \& Youniss, J. (2010). Toward a political theory of political socialization of youth. In L. R. Sherrod, J. Torney-Purta, \& C. A. Flanagan (Eds.), Handbook of research on civic engagement in youth (pp. 23-41). Hoboken: John Wiley \& Sons. https://doi.org/10.3152/030234209X460962.

Miller, J. D. (2012). The sources and impact of civic scientific literacy. In M. W. Bauer, R. Shukla, \& N. Allum (Eds.), The culture of science. How the public relates to science across the globe (pp. 217-240). https://doi. org/10.4324/9780203813621.

Molina, L. M., Lloréns-Montes, J., \& Ruiz-Moreno, A. (2007). Relationship between quality management practices and knowledge transfer. Journal of Operations Management. https://doi.org/10.1016/j. jom.2006.04.007.

Muis, K. R., Winne, P. H., \& Jamieson-Noel, D. (2007). Using a multitrait-multimethod analysis to examine conceptual similarities of three self-regulated learning inventories. The British Journal of Educational Psychology. https://doi.org/10.1348/000709905X90876.

Muthén, L. K., Muthén, B. O. (2015). Mplus user's guide. Seventh edition. Los Angeles: Author. Los Angeles, CA: Muthén \& Muthén

Notley, T., Dezuanni, M., Zhong, H. F., \& Howden, S. (2017). News and Australian children: How young people access, perceive and are affected by the news. Sidney: Crinkling News.

Olitsky, S., \& Milne, C. (2012). Understanding engagement in science education: The psychological and the social. In B. J. Fraser, K. G. Tobin, \& C. J. McRobbie (Eds.), Second international handbook of science education (pp. 19-33). https://doi.org/10.1007/978-1-4020-9041-7_2.

Osborne, J., \& Dillon, J. (2008). Science education in Europe: Critical reflections. London: The Nuffield Foundation.

Osborne, J., Simon, S., \& Collins, S. (2003). Attitudes towards science: A review of the literature and its implications. International Journal of Science Education. https://doi.org/10.1080/0950069032000032199.

Ottander, C., \& Ekborg, M. (2012). Students' experience of working with socioscientific issues-a quantitative study in secondary school. Research in Science Education. https://doi.org/10.1007/s11165-011-9238-1.

Özden, M. (2015). Prospective elementary school teachers' views about socioscientific issues: A concurrent parallel design study. International Electronic Journal of Elementary Education, 7(3), 333-354.

Parr, J. C. (2014). View of socioscientific issues among educators: The willingness of teachers to accept SSI into the classroom and the reasoning underlying those beliefs (dissertation). The University of Southern Mississippi.

Post, T., \& Walma van der Molen, J. H. (2019). Development and validation of a questionnaire to measure primary school children's images of and attitudes towards curiosity (the CIAC questionnaire). Motivation and Emotion. https://doi.org/10.1007/s11031-018-9728-9.

Prudon, P. (2015). Confirmatory factor analysis as a tool in research using questionnaires: A critique. Comprehensive Psychology. https://doi.org/10.2466/03.CP.4.10.

Putnick, D. L., \& Bornstein, M. H. (2016). Measurement invariance conventions and reporting: The state of the art and future directions for psychological research. Developmental Review. https://doi.org/10.1016/j. dr.2016.06.004.

Rahayu, S., Setyaningsih, A., Astarina, A. D., \& Fathi, M. N. (2018). High school students' attitudes about socioscientific issues contextualized in inquiry-based chemistry instruction. In Proceedings of the 2nd 
International Conference on Education and Multimedia Technology - ICEMT 2018 (pp. 80-84). https://doi. org/10.1145/3206129.3239436.

Raykov, T. (1997). Estimation of composite reliability for congeneric measures. Applied Psychological Measurement. https://doi.org/10.1177/01466216970212006.

Romine, W. L., Sadler, T. D., \& Kinslow, A. T. (2017). Assessment of scientific literacy: Development and validation of the Quantitative Assessment of Socio-Scientific Reasoning (QuASSR). Journal of Research in Science Teaching. https://doi.org/10.1002/tea.21368.

Rundgren, S. N. C. (2011). How does background affect attitudes to socioscientific issues in Taiwan? Public Understanding of Science. https://doi.org/10.1177/0963662509359998.

Ryan, A. M., \& Spash, C. L. (2012). The awareness of consequences scale: An exploration, empirical analysis, and reinterpretation. Journal of Applied Social Psychology. https://doi.org/10.1111/j.15591816.2012.00951.x.

Sadler, T. D. (2004). Informal reasoning regarding socioscientific issues: A critical review of research. Journal of Research in Science Teaching. https://doi.org/10.1002/tea.20009.

Sadler, T. D. (2009). Situated learning in science education: Socio-scientific issues as contexts for practice. Studies in Science Education. https://doi.org/10.1080/03057260802681839.

Sadler, T. D. (2011). Socio-scientific issues in the classroom: teaching, learning and research (Vol. 39). https://doi.org/10.1007/978-94-007-1159-4.

Sadler, T. D., Foulk, J. A., \& Friedrichsen, P. J. (2017). Evolution of a model for socio-scientific issue teaching and learning. International Journal of Education in Mathematics, Science and Technology. https://oi. org/10.18404/ijemst.55999.

Schulz, W., Ainley, J., Fraillon, J., Kerr, D., \& Losito, B. (2010). ICCS 2009 International report: Civic knowledge, attitudes, and engagement among lower-secondary school students in 38 countries. Amsterdam: International Association for the Evaluation of Educational Achievement.

Schwarz, N. (2007). Attitude construction: Evaluation in context. Social Cognition. https://doi.org/10.1521 /soco.2007.25.5.638.

Sinatra, G. M., Heddy, B. C., \& Lombardi, D. (2015). The challenges of defining and measuring student engagement in science. Educational Psychologist. https://doi.org/10.1080/00461520.2014.1002924.

Steinmetz, H., Knappstein, M., Ajzen, I., Schmidt, P., \& Kabst, R. (2016). How effective are behavior change interventions based on the theory of planned behavior?: A three-level meta analysis. Zeitschrift Fur Psychologie. https://doi.org/10.1027/2151-2604/a000255.

Stenseth, T., Bråten, I., \& Strømsø, H. I. (2016). Investigating interest and knowledge as predictors of students' attitudes towards socio-scientific issues. Learning and Individual Differences. https://doi.org/10.1016/j. lindif.2016.02.005.

Subiantoro, A. W. (2017). Promoting socio-scientific issues-based learning in biology: Indonesian students' and teacher's perceptions and students' informal reasoning (dissertation). Curtin University.

Szagun, G., \& Pavlov, V. I. (1995). Environmental awareness: A comparative study of German and Russian adolescents. Youth Society. https://doi.org/10.1177/0044118X95027001006.

Topçu, M. S. (2010). Development of attitudes towards socioscientific issues scale for undergraduate students. Evaluation \& Research in Education. https://doi.org/10.1080/09500791003628187.

Topçu, M. S., Yilmaz-Tuzun, O., \& Sadler, T. D. (2011). Turkish preservice science teachers' informal reasoning regarding socioscientific issues and the factors influencing their informal reasoning. Journal of Science Teacher Education. https://doi.org/10.1007/s10972-010-9221-0.

Trochim, W. M. K., \& Donnelly, J. P. (2006). Research methods knowledge base (3rd ed.). Boston: Cengage Learning.

Van Aalderen-Smeets, S. I., Walma van der Molen, J. H., \& Asma, L. J. F. (2012). Primary teachers' attitudes toward science: A new theoretical framework. Science Education. https://doi.org/10.1002/sce.20467.

Van den Wijngaard, O., Beausaert, S., Segers, M., \& Gijselaers, W. (2015). The development and validation of an instrument to measure conditions for social engagement of students in higher education. Studies in Higher Education. https://doi.org/10.1080/03075079.2013.842214.

Vandenberg, R. J., \& Lance, C. E. (2000). A review and synthesis of the measurement invariance literature: Suggestions, practices, and recommendations for organizational research. Organizational Research Methods. https://doi.org/10.1177/109442810031002.

Velayutham, S., Aldridge, J., \& Fraser, B. (2011). Development and validation of an instrument to measure students' motivation and self-regulation in science learning. International Journal of Science Education. https://doi.org/10.1080/09500693.2010.541529.

Vesterinen, V. M., Tolppanen, S., \& Aksela, M. (2016). Toward citizenship science education: What students do to make the world a better place? International Journal of Science Education. https://doi.org/10.1080 /09500693.2015.1125035.

Vogel, T., \& Wänke, M. (2016). Attitudes and attitude change. Hove: Psychology Press. 
Walma van der Molen, J. H., Valkenburg, P. M., \& Peeters, A. L. (2002). Television news and fear: A child survey. Communications. https://doi.org/10.1515/comm.27.3.303.

Watts, R. J., \& Flanagan, C. (2007). Pushing the envelope on youth civic engagement: A developmental and liberation psychology perspective. Journal of Community Psychology. https://doi.org/10.1002/jcop.20178.

Wilkenfeld, B., Lauckhardt, J., \& Torney-Purta, J. (2010). The relation between developmental theory and measures of civic engagement in research on adolescents. In L. R. Sherrod, J. Torney-Purta, \& C. A. Flanagan (Eds.), Handbook of research on civic engagement in youth (pp. 193-219). https://doi.org/10.1002 /9780470767603.ch8.

Worthington, R. L., \& Whittaker, T. A. (2006). Scale development research: A content analysis and recommendations for best practices. The Counseling Psychologist. https://doi.org/10.1177/0011000006288127.

Wray-Lake, L., Flanagan, C. A., \& Osgood, D. W. (2010). Examining trends in adolescent environmental attitudes, beliefs, and behaviors across three decades. Environment and Behavior. https://doi.org/10.1177 /0013916509335163.

Xiao, S., \& Sandoval, W. A. (2017). Associations between attitudes towards science and children's evaluation of information about socioscientific issues. Science Education. https://doi.org/10.1007/s11191-017-9888-0.

Yu, C.-Y. (2002). Evaluating cutoff criteria of model fit indices for latent variable models with binary and continuous outcomes (dissertation). University of California.

Zeidler, D. L. (2014). Socioscientific issues as a curriculum emphasis: Theory, research and practice. In N. G. Lederman \& S. K. Abell (Eds.), Handbook of research on science education (Vol. 2, pp. 697-726). https://doi.org/10.4324/9780203097267.ch34.

Zeidler, D. L. (2016). STEM education: A deficit framework for the twenty first century? A sociocultural socioscientific response. Cultural Studies of Science Education. https://oi.org/10.1007/s11422-014-9578-z.

Zeidler, D. L., \& Nichols, B. H. (2009). Socioscientific issues: Theory and practice. Journal of Elementary Science Education. https://doi.org/10.1007/BF03173684.

Zeidler, D. L., \& Sadler, T. D. (2008). Social and ethical issues in science education: A prelude to action. Science \& Education. https://doi.org/10.1007/s11191-007-9130-6.

Zeidler, D. L., Sadler, T. D., Simmons, M. L., \& Howes, E. V. (2005). Beyond STS: A research-based framework for socioscientific issues education. Science Education. https://doi.org/10.1002/sce.20048.

Publisher's Note Springer Nature remains neutral with regard to jurisdictional claims in published maps and institutional affiliations. 